\section{Mapping shows continued vineyard expansion in premium wine-growing areas}

A erial photography and mapping show that the increased demand for premium wines is reflected on the ground in Sonoma County (see page 12). There, as in other coastal counties, vineyard acreage increased dramatically during the 1990s and into the early 2000s.

"While expansion rates have decreased in Sonoma County in recent years, mapping of vineyards from aerial photos and analysis of data published by the county agricultural commissioner show that new vineyards continue to be planted," says Emily Heaton, doctoral student in the UC Berkeley Department of Environmental Science, Policy and Management. Heaton has been mapping Sonoma County vineyards from aerial photos as part of her work in the lab of Adina Merenlender, Associate Cooperative Extension Specialist.

Their research, which is affiliated with the UC Integrated Hardwood Range Management Program, focuses on the environmental impacts of habitat conversion. "Knowing the location of vineyards and other land cover types helps us research the impacts of land use on the environment," Merenlender says.

To obtain the most accurate estimates of vineyard acreage, the researchers use digital, orthorectified aerial photos from 1993, 2000, 2002, 2004 and 2005, as well as oblique aerial photos from 2006. The photographs are matched on-screen with mapped landmarks such as roads and hilltops, which ensures that the boundaries of mapped vineyards are spatially accurate.

The ongoing mapping effort shows that at least 5,160 acres of vineyards have been planted in Sonoma County since 2000. This represents $8.7 \%$ of the 59,000 vineyard acres that have been mapped so far. "While many new projects occurred in the more established premium-winegrape areas such as Alexander Valley and Sonoma Valley, there has also been a significant increase in areas that were not historically important, such as the Sonoma Coast and land surrounding Petaluma," Heaton says.

Coastal areas with cool conditions favorable for pinot noir seem to be particularly attractive. Some observers call it the "Sideways" effect, due to the popular 2004 movie that touted California pinot noir. For example, for the portion of the Sonoma Coast appellation that lies north of the
Russian River and west of Monte Rio, vineyard acreage increased by 351 acres during 2000-2006 to a total of 1,028 acres, a $51.6 \%$ increase. In addition, the clearing of forestland for additional vineyards is evident in 2006 imagery, Heaton says.

"Historically, the Sonoma Coast was not an important wine-grape region — only about 200 acres existed in the analysis area in 1993," Heaton says. "But a small number of vintners and wineries have proven that high-quality pinot can be grown successfully on the coast."

Merenlender adds, "The business environment for timber production has become a lot more difficult due to historic overharvesting, volatile wood markets and stricter environmental rules. A lot of coastal forest land is going up for sale, cheaply."

Coastal watersheds provide habitat for salmon, and vineyard conversions can alter natural water flows that are needed to support spawning and fish growth, Merenlender says. Vineyards often pump water from the ground during the dry season, potentially limiting survival of juvenile fish.

Recent vineyard expansion has also occurred in other coastal counties that produce premium wine-grapes. Based primarily on agriculture commissioner reports (not aerial mapping), Central Coast vineyard acreage expanded from an estimated 26,800 acres in San Luis Obispo County in 2000 to 36,493 acres in 2006, a 32\% increase. Santa Barbara County's vineyard acreage increased from 9,542 acres in 1990 to an estimated 21,000+ acres in 2007.

On the North Coast, Napa County's vineyard acreage increased from 32,715 acres in 1990 to 45,136 in 2006. Lake County's acreage went from 7,335 in 2002 to 8,529 in 2005. Finally, in Mendocino County, acreage increased from 12,608 in 1991 to 16,446 in 2001 and 16,783 in 2006.

"We use this data on the rate and extent of land-use change to quantify environmental impacts and to forecast future land-use patterns, in an effort to improve conservation planning," Merenlender says.
- Editors

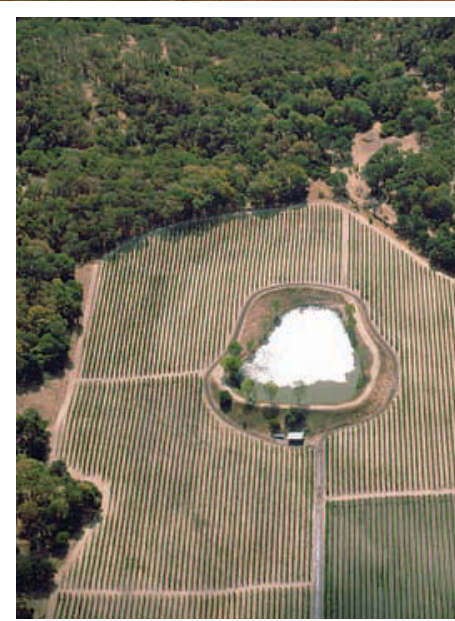

Aerial photographs are used by UC researchers to evaluate land-use changes, such as the conversion of forest lands to vineyards. Top, the Sonoma Coast (no vineyards shown); middle, the mainstem of the Russian River surrounded by vineyards; bottom, a small reservoir among newly planted vines in Sonoma County. 